\title{
Low level of attention to health inequalities in prevention planning activities of the Italian Regions
}

\author{
Corrado De Vito, Azzurra Massimi, Domitilla Di Thiene, Annalisa Rosso, Elvira D’Andrea, Maria Rosaria Vacchio,
} Paolo Villari ${ }^{*}$ and Carolina Marzuillo

\begin{abstract}
Background: Health promotion and prevention activities should tackle health inequalities to reduce disparities in health among disadvantaged populations. This study aimed to assess the extent to which the Italian Regions considered health inequalities during the planning of prevention activities, to detect geographical differences and to identify the possible determinants of differences in attention to health inequalities.

Methods: The 19 Regional Prevention Plans (RPPs) developed by Italian Regions within the National Prevention Plan (NPP) 2010-2013 were assessed using a specific tool to address the level of attention to health inequalities. Univariate and multivariate analyses were performed to identify regional characteristics associated with a higher level of attention to health inequalities.

Results: Of the 702 projects included in the 19 RPPs, only 56 (8.0 \%) specifically addressed issues related to health inequalities. The results of the multivariate analysis showed that a higher level of attention was associated with the macroarea of intervention 'prevention in high-risk groups', with the higher quality of the Strategic Plan Section of the RPP and with the higher percentage of migrants in the Region in 2010. Moreover, projects that addressed the topic of health inequalities were more likely to be developed in the Northern Regions, in Regions with a lower level of 'linking social capital' and with a Higher Regional Health Care Expenditure (RHCE) as a percentage of Regional Gross Domestic Product (RGDP) in 2010.

Conclusions: The level of attention to health inequalities in the regional planning process of prevention activities 2010-2013 in Italy is low. The results of this study supported the new round of prevention planning in Italy, and highlight the urgent need to increase the number of policies and interventions able to reduce health inequalities.
\end{abstract}

Keywords: Prevention, Health inequalities, National Prevention Plan

\section{Background}

A comparison of 22 European countries showed that health inequalities associated with socioeconomic status are present everywhere throughout Europe, highlighting the urgent need for public health research to find effective policies and interventions able to reduce health inequalities $[1,2]$. The first report on inequalities in health in Italy, published in 1994, found a strong association between illness and conditions of social and economic disadvantage for all health indicators [3]. A study

\footnotetext{
* Correspondence: paolo.villari@uniroma1.it

Department of Public Health and Infectious Diseases, Sapienza University of

Rome, Piazzale Aldo Moro 5, Rome 00185, Italy
}

published ten years later reported that mortality in Italy increased with social disadvantage for a wide range of indicators at both the individual (education, social class, income) and geographical (deprivation indexes) levels [4]. In Italy today, the most important behavioral risk factors for chronic diseases are more common in the Southern Regions and among the economically disadvantaged and less educated groups, whose death risk is about $80 \%$ higher than the general population [5].

Addressing health inequalities has become a priority for several high-income countries, with emphasis on health promotion and prevention activities [6-8]. However, the development of interventions specifically aimed 
at tackling health inequalities is very challenging, given that the evidence prompting their development is mainly descriptive and that the interventions themselves are focused on modifying lifestyle factors $[9,10]$. A recent umbrella review that synthesized the results of thirty systematic reviews of the effects on health inequalities of any intervention based on wider social determinants of health (e.g., housing, living environment, working conditions, etc.) found unclear effects of these interventions, and called for more studies on this topic [9]. Nevertheless, positive effects on the health of disadvantaged individuals have resulted from interventions aimed at reducing exposure to risk factors in the whole population [11-13].

The National Prevention Plan (NPP) is the main policy and planning instrument for prevention in Italy. Issued approximately every 3-5 years, the NPP is the part of the National Health Plan (NHP), which is committed to the development of health promotion and disease prevention activities [14]. In accordance with the Italian institutional framework of healthcare decentralization, the NPP 2010-2012 (extended to 2013) determined that each Italian Region should develop its own Regional Prevention Plan (RPP), designing projects coherent with the regional epidemiological and organizational context. RPPs and their projects offer a unique opportunity to assess the extent to which the Italian Regions considered health inequalities during the planning of prevention activities. The specific objectives of this study were to assess the level of attention to inequalities in RPP projects, to detect geographical differences and to identify the possible determinants of differences in attention to health inequalities.

\section{Methods}

This study is part of a wider project funded by the Italian Ministry of Health aimed at identifying strengths and weaknesses of the prevention planning process in Italy, and at providing suggestions for strengthening regional capacities. These outcomes should prove useful for subsequent rounds of prevention planning.

A tool specifically designed by a Scientific Committee appointed by the Italian Ministry of Health was used to appraise the 19 RPPs. Descriptions of the structure of the RPPs and the methodology used to develop the tool are presented elsewhere [15]. Briefly, RPPs have two core sections: i) a Strategic Framework Section, which deals with the analysis of the regional context, identification of local needs, description of regional health planning and definition of priorities for the RPP 2010-2012; and ii) an Operational Plan Section, in which projects are developed as a consequence of the planning choices set out in the Strategic Framework Section [15]. The appraisal tool reflects the structure of the RPPs and thus also has two sections: i) a descriptive analysis of the RPP, focused mainly on the Strategic Framework Section; and ii) an analysis of the projects included in the Operational Plan Section of the RPP [16]. The analysis of each RPP was carried out by working groups composed of at least two independent members, with discrepancies resolved by discussion.

Data analysis was carried out with two objectives: i) to describe to what extent RPP projects consider health inequalities and specific public health issues in vulnerable populations; ii) to identify regional characteristics that may be associated with the different levels of attention paid to health inequalities in RPP projects. Projects are required to match one or more of 22 general lines of intervention grouped into four macroareas (Predictive medicine, Universal prevention, Prevention in high risk groups and Prevention of complications and recurrence of chronic diseases).

The level of attention to inequalities in RPP projects was evaluated using the following three Yes/No questions taken from a specific tool for the assessment of the attention to equity of prevention projects based on international guidelines [17-19] and adapted to the Italian context [20]: i) Did the project include activities aimed at solving public health problems in vulnerable populations? (i.e., did the project discuss on the burden of disease in disadvantaged populations and include activities to reduce it?) [17]; ii) Was the project aimed at improving the access of vulnerable groups to health services? (i.e., did the project discuss barriers to implementation in disadvantaged populations, and identify strategies to overcome these barriers?) [17]; iii) Did the project include an evaluation of its impact on vulnerable populations? (i.e., did the project contain plans for monitoring disadvantaged groups according to place of residence, race, occupation, gender, religion, education, socioeconomic status, or social network and capital?) [17]. A fourth question (iv) was added to identify whether projects were specifically aimed at the reduction of health inequalities.

To identify regional characteristics associated with the degree of consideration of health inequalities, a dichotomous variable was obtained by assigning to each project a value of 1 if there was a positive answer to at least one of the four questions described above. Statistical analysis was carried out by univariate and multiple logistic regression analyses.

Student's $t$-test (for continuous variables) and $\chi^{2}$ test (for categorical variables) were used to evaluate the association between attention to inequalities in RPP projects and the following set of variables, some of which are based on the most reliable institutional indicators for the description of the socioeconomic status of the Regions: 
i) macroarea of intervention (Predictive medicine, Universal prevention, Prevention in high-risk groups and Prevention of complications and recurrence of chronic diseases);

ii) geographic area (North, Center, South and Islands);

iii) quality of the Strategic Framework section of the RPP. In order to adjust the model for the quality of the RPPs, we considered 21 items of the appraisal tool of the Strategic Framework Section of the RPP. A principal component analysis (PCA) was performed to reduce the number of items. The following 10 items were retained: regional demographical context clearly described; regional socio-economic context clearly described; regional epidemiological context clearly described; organizational context clearly described; organizational needs clearly stated; epidemiological needs clearly stated; information on regional health programming provided; criteria used to establish the priorities clearly stated; all identified needs and priorities translated into specific projects; the RPP reported the results of the previous RPP. The $0-10$ summary score was calculated and included in the model as a dichotomous variable (high if above the median, low-medium if below). The complete methodology is described in detail elsewhere [21];

iv) regional Gini index in 2010 [22] (categorized in quartiles);

v) presence of a formal Recovery Plan in the Region, imposed by the Central Government as a consequence of a regional structural deficit in the health care budget to establish objectives and strategic actions by which Regions might restore financial equilibrium and remove determinants of structural imbalance [21];

vi) regional health care expenditure (RHCE) as a percentage of Regional Gross Domestic Product (RGDP) in 2010 (continuous) [22];

vii)percentage of migrants of the total population in the Region in 2010 (continuous) [22];

viii) regional deprivation index in 2010 (continuous) [22];

ix) regional score of civicness, using the most updated score derived by Putnam et al. [23], which, based on a series of indexes extracted by the National Health Interview Survey 2007 [24], is intended to measure the so-called 'linking social capital' of the Region [25]; this score describes the vertical relationships connecting individuals, or the social networks to which they belong, to people or groups who are in positions of political power or status [24]. This aspect of civicness plays a crucial role in the economic growth of [26], the increase of trust in [27] and the performance of the institutions concerned [28].
A multiple logistic regression model was built to identify the regional characteristics associated with attention to health inequalities in RPPs projects. All the aforementioned variables were included in the model. Interaction terms were tested using a cut-off significance level of 0.15 and robust standard errors were estimated to adjust for the regional (cluster) effect. Tolerance and variance inflation factor (VIF) were measured to estimate multicollinearity among independent variables. Adjusted odds ratios (ORs) and $95 \%$ confidence intervals (CIs) were calculated. Statistical analysis was performed using STATA statistical software, version 12.0 (Stata Corp. LP, College Station, TX. USA, 2011).

\section{Results}

Of the 702 projects included in the 19 RPPs developed by the Italian Regions, only 56 (8.0 \%) addressed at least one of the four issues related to health inequalities (Table 1). Emilia Romagna Region addressed the highest percentage of projects in its RPP to the problems of health inequalities $(21.8 \%)$, while at the other extreme two Regions (Basilicata and Sardegna) developed no projects of this type. Across all Regions, only 13 projects $(1.9 \%)$ were specifically aimed at the reduction of inequalities, six of which were developed by Emilia Romagna. The majority of the projects included activities aimed at solving public health problems relevant to vulnerable populations $(42,6.0 \%)$ and aimed at improving the access of vulnerable populations to health services (38, 5.4 \%). Only six Regions (Liguria, Emilia Romagna, Toscana, Umbria, Marche and Calabria) developed projects (21 overall, $3.0 \%)$ that evaluated their impact on vulnerable populations (Table 1 ).

Univariate and multivariate analyses allowed us to examine the association of attention to inequalities in RPP projects with several variables. Projects addressing health inequalities were more frequent in the macroarea of 'prevention in high-risk groups', and were associated with a higher quality of the Strategic Plan section of the RPP. Moreover, the percentage of migrants in the regional population was higher for projects which devoted attention to inequalities. Geographic macroarea, regional Gini index, presence of a Recovery plan in the Region, regional healthcare expenditure as a percentage of RGDP and deprivation index showed no significant impact according to the univariate analysis (Table 2).

Multiple logistic regression analysis confirmed the statistically significant association of the level of attention to inequalities in projects with the macroarea of intervention 'prevention in high-risk groups', with higher quality of the Strategic Plan section of the RPP and with higher percentage of migrants in the Region (Table 3). Moreover, projects that considered health inequalities were significantly more likely to be developed by Northern 
Table 1 Descriptive analysis of projects included in the Regional Prevention Plans (RPPs) that addressed the reduction of inequalities and specific public health issues concerning vulnerable populations

\begin{tabular}{|c|c|c|c|c|c|c|}
\hline \multirow[t]{2}{*}{ Region } & \multirow[t]{2}{*}{$\begin{array}{l}\text { Total number of project } \\
\text { included in the RPP }\end{array}$} & $\begin{array}{l}\text { Projects specifically aimed at } \\
\text { the reduction of inequalities }\end{array}$ & \multirow{2}{*}{$\begin{array}{l}\text { Projects that included activities } \\
\text { aimed at solving public health } \\
\text { problems in vulnerable populations } \\
\text { N (\%) }\end{array}$} & \multirow{2}{*}{$\begin{array}{l}\text { Projects aimed at improving the } \\
\text { access of vulnerable groups to } \\
\text { health services } \\
\mathrm{N}(\%)\end{array}$} & \multirow{2}{*}{$\begin{array}{l}\text { Projects that had an impact } \\
\text { evaluation on vulnerable } \\
\text { population } \\
\text { N (\%) }\end{array}$} & \multirow{2}{*}{$\begin{array}{l}\text { Total number of project } \\
\text { addressing at least one } \\
\text { of the four issues relatec } \\
\text { to inequalities } \\
\mathrm{N}(\%)\end{array}$} \\
\hline & & N (\%) & & & & \\
\hline \multicolumn{7}{|l|}{$\overline{\mathrm{NORTH}}$} \\
\hline Piemonte & 64 & $2(3.1)$ & $4(6.3)$ & $2(3.1)$ & $0(0)$ & $4(6.3)$ \\
\hline Lombardia & 23 & $0(0)$ & $3(13.0)$ & $2(8.7)$ & $0(0)$ & $3(13.0)$ \\
\hline A.P. Trento ${ }^{a}$ & 32 & $1(3.1)$ & $0(0)$ & $1(3.1)$ & $0(0)$ & $2(6.2)$ \\
\hline Veneto & 71 & $0(0)$ & $1(1.4)$ & $0(0)$ & $0(0)$ & $1(1.4)$ \\
\hline $\mathrm{FVG}^{\mathrm{b}}$ & 19 & $0(0)$ & $3(15.8)$ & $1(5.3)$ & $0(0)$ & $3(15.8)$ \\
\hline Liguria & 40 & $1(2.5)$ & $6(15.0)$ & $6(15.0)$ & $7(12.5)$ & $6(15.0)$ \\
\hline Emilia Romagna & 55 & $6(10.9)$ & $9(16.4)$ & $9(16.4)$ & $9(16.4)$ & $12(21.8)$ \\
\hline \multicolumn{7}{|l|}{ CENTER } \\
\hline Toscana & 49 & $1(2.0)$ & $2(4.1)$ & $2(4.1)$ & $2(4.1)$ & $2(4.1)$ \\
\hline Umbria & 27 & $0(0)$ & $2(7.4)$ & $1(3.7)$ & $1(3.7)$ & $2(7.4)$ \\
\hline Marche & 30 & $0(0)$ & $2(6.7)$ & $5(16.7)$ & $0(0)$ & $5(16.7)$ \\
\hline Lazio & 22 & $1(4.6)$ & $2(9.1)$ & $2(9.1)$ & $1(4.6)$ & $2(9.0)$ \\
\hline \multicolumn{7}{|l|}{ SOUTH } \\
\hline Abruzzo & 21 & $0(0)$ & $0(0)$ & $1(4.8)$ & $0(0)$ & $1(4.8)$ \\
\hline Molise & 31 & $0(0)$ & $1(3.2)$ & $0(0)$ & $0(0)$ & $1(3.2)$ \\
\hline Campania & 42 & $0(0)$ & $3(7.1)$ & $5(11.9)$ & $0(0)$ & $6(14.3)$ \\
\hline Puglia & 39 & $0(0)$ & $1(2.6)$ & $0(0)$ & $0(0)$ & $1(2.6)$ \\
\hline Basilicata & 19 & $0(0)$ & $0(0)$ & $0(0)$ & $0(0)$ & $0(0)$ \\
\hline Calabria & 70 & $1(1.4)$ & $2(2.9)$ & $1(1.4)$ & $3(4.3)$ & $4(5.7)$ \\
\hline \multicolumn{7}{|l|}{ ISLANDS } \\
\hline Sardegna & 18 & $0(0)$ & $0(0)$ & $0(0)$ & $0(0)$ & $0(0)$ \\
\hline Sicilia & 30 & $0(0)$ & $1(3.3)$ & $0(0)$ & $0(0)$ & $1(3.3)$ \\
\hline TOTAL & 702 & $13(1.9)$ & $42(6.0)$ & $38(5.4)$ & $21(3.0)$ & $56(8.0)$ \\
\hline
\end{tabular}

${ }^{a}$ A.P. Trento Autonomous Province of Trento

${ }^{\mathrm{b}}$ FVG Friuli Venezia-Giulia 
Table 2 Analysis of projects included in the Regional Prevention Plans (RPPs) that addressed the reduction of inequalities and specific public health issues concerning vulnerable populations, according to selected variables

\begin{tabular}{|c|c|c|c|}
\hline \multirow[t]{3}{*}{ Variables } & \multicolumn{2}{|c|}{ Projects with attention to inequalities $^{a}$} & \multirow{3}{*}{$\mathrm{pV}$} \\
\hline & No & Yes & \\
\hline & N. (\%) & N. (\%) & \\
\hline \multicolumn{4}{|l|}{ Macroarea of intervention } \\
\hline Predictive medicine & $34(97.1)$ & $1(2.9)$ & \multirow[t]{4}{*}{$<0.001^{*}$} \\
\hline Universal prevention & $415(94.3)$ & $25(5.7)$ & \\
\hline Prevention in populations at risk & $163(84.9)$ & $29(15.1)$ & \\
\hline Tertiary prevention ${ }^{\mathrm{b}}$ & $34(97.1)$ & $1(2.9)$ & \\
\hline \multicolumn{4}{|l|}{ Geographic area } \\
\hline North & $274(90.1)$ & $30(9.9)$ & \multirow[t]{4}{*}{0.198} \\
\hline Center & $117(91.4)$ & $11(8.6)$ & \\
\hline South & $208(93.7)$ & $14(6.3)$ & \\
\hline Islands & $47(97.9)$ & $1(2.1)$ & \\
\hline \multicolumn{4}{|c|}{ Quality score of the Strategic Plan section of the RPP } \\
\hline Low/medium & $448(94.3)$ & $27(5.7)$ & \multirow[t]{2}{*}{$0.001^{*}$} \\
\hline High & $198(87.2)$ & $29(12.8)$ & \\
\hline \multicolumn{4}{|l|}{ Regional Gini index } \\
\hline $1^{\text {st }}$ quartile & $142(93.4)$ & $10(6.6)$ & \multirow[t]{4}{*}{0.172} \\
\hline $2^{\text {nd }}$ quartile & $193(91.9)$ & $17(8.1)$ & \\
\hline $3^{\text {rd }}$ quartile & $145(87.4)$ & $21(12.6)$ & \\
\hline $4^{\text {th }}$ quartile & $162(93.1)$ & $12(6.9)$ & \\
\hline \multicolumn{4}{|l|}{ Recovery Plan in the Region } \\
\hline No & $348(90.9)$ & $35(9.1)$ & \multirow[t]{3}{*}{0.213} \\
\hline \multirow[t]{2}{*}{ Yes } & $298(93.4)$ & $21(6.6)$ & \\
\hline & Mean (SD) & Mean (SD) & \\
\hline \multicolumn{4}{|c|}{ Regional health care expenditure as \% of the RGDPd } \\
\hline (continuous) & $8.1(2.0)$ & $7.7(1.9)$ & 0.121 \\
\hline \multicolumn{4}{|l|}{ Percentage of migrants in the Region } \\
\hline (continuous) & $7.1(3.4)$ & $8.0(3.2)$ & $0.046^{* *}$ \\
\hline \multicolumn{4}{|l|}{ Deprivation index } \\
\hline (continuous) & $15.6(7.0)$ & $14.3(7.1)$ & 0.203 \\
\hline
\end{tabular}

${ }^{\mathrm{a}} \mathrm{See}$ text for definition

${ }^{\mathrm{b}}$ Tertiary prevention: Prevention of complications and recurrence of diseases

${ }^{C} R P P$ Regional Prevention Plan

${ }^{\mathrm{d}} R G D P$ Regional Gross Domestic Product

${ }^{*} p V<0.05$ (Chi-square test)

${ }^{* *} p \mathrm{~V}<0.05$ (Student's $t$ test)

Regions, and by Regions with a higher RHCE as a percentage of RGDP and with a lower level of civicness. The variable 'regional deprivation index', originally included in the model, was excluded due to collinearity (VIF: 30.22; tolerance: 0.03$)$. No other variables showed critical tests' results (Table 3 ).

\section{Discussion}

Multidisciplinary actions and policies which aim to counteract the various mechanisms that trigger inequalities and to reduce the impact of social inequality on health are among the priority actions of the health policy framework recently developed by the WHO regional office for Europe [29]. This approach needs strong health ministries, modern public health infrastructures and high-performing and equity-oriented health systems [30]. The urgent requirement for public health leaders able to understand the importance of programming targeted at the structural determinants of health has also been strongly emphasised in countries outside Europe, such as Canada [31] and 
Table 3 Results of the multiple regression model investigating possible predictors of the attention to inequalities of projects included in the Regional Prevention Plans (RPPs)

\begin{tabular}{|c|c|c|c|}
\hline & OR & $95 \% \mathrm{Cl}$ & $\mathrm{pV}$ \\
\hline \multicolumn{4}{|l|}{ Macroarea of intervention } \\
\hline Universal prevention (reference) & 1.00 & - & - \\
\hline Predictive medicine & 0.40 & $0.04-3.74$ & 0.420 \\
\hline Prevention in high risk groups & 3.14 & $1.73-5.73$ & $<0.001$ \\
\hline Prevention of complications and recurrence of chronic diseases & 0.45 & $0.05-4.08$ & 0.476 \\
\hline \multicolumn{4}{|l|}{ Geographic area } \\
\hline North (reference) & 1.00 & - & - \\
\hline Center & 0.52 & $0.29-0.94$ & 0.031 \\
\hline South & 0.69 & $0.22-2.21$ & 0.534 \\
\hline Islands & 0.12 & $0.03-0.51$ & 0.004 \\
\hline \multicolumn{4}{|l|}{ Quality score of the Strategic Plan section of the RPPa } \\
\hline Low (reference) & 1.00 & - & - \\
\hline High & 2.51 & $1.42-4.43$ & 0.002 \\
\hline \multicolumn{4}{|l|}{ Regional Gini index } \\
\hline $1^{\text {st }}$ quartile (reference) & 1.00 & - & - \\
\hline $2^{\text {nd }}$ quartile & 1.25 & $0.45-3.48$ & 0.671 \\
\hline $3^{\text {rd }}$ quartile & 0.86 & $0.33-2.25$ & 0.757 \\
\hline $4^{\text {th }}$ quartile & 1.81 & $0.56-5.92$ & 0.324 \\
\hline \multicolumn{4}{|l|}{ Recovery plan in the Region } \\
\hline No & 1.00 & - & - \\
\hline Yes & 1.22 & $0.38-3.88$ & 0.735 \\
\hline \multicolumn{4}{|l|}{ Regional health care expenditure as \% of RGDP } \\
\hline Continuous & 1.51 & $1.02-2.24$ & 0.041 \\
\hline \multicolumn{4}{|l|}{ Percentage of migrants in the Region } \\
\hline Continuous & 1.48 & $1.08-2.03$ & 0.016 \\
\hline \multicolumn{4}{|l|}{ Score of civicness } \\
\hline Continuous & 0.73 & $0.46-0.97$ & 0.031 \\
\hline
\end{tabular}

${ }^{\mathrm{a}}$ RPP Regional Prevention Plan

${ }^{\mathrm{b}} R G D P$ Regional Gross Domestic Product

Note: the variable 'regional deprivation index' was excluded due to collinearity

Australia [32]. In the latter, a review found that government initiatives on prevention were more likely to be focused on individual behaviours linked to chronic diseases than on socioeconomic and cultural factors that drive such behaviours and, ultimately, disease outcomes [32].

Measures to combat inequalities have been adopted at the national level in Italy, but almost exclusively within the Health Service, rarely with the support of other areas and never as part of a comprehensive strategy. Instead of preventing the effect of social inequalities, in particular through health policies aimed at protecting the wellbeing of vulnerable groups, most actions focus on repairing the consequences of inequity, often without a clear and direct interest in reducing the gap in health between social groups [5].
The level of attention to the reduction of health inequalities showed by projects developed by Italian Regions within their RPPs was very low, since only $8.0 \%$ of the projects showed specific attention to differences in health profiles among population subgroups and made proposals for the reduction of inequalities. Of particular interest is that these projects were more likely to be developed by Northern Regions, those with a higher percentage of migrants, those with a higher RHCE as a percentage of RGDP and those with a lower level of civicness. Moreover, projects that devoted attention to inequalities were more frequently in the macroarea of prevention in population at risk.

We found an association between a high percentage of migrants in the Region and a higher level of attention to 
inequalities in RPP projects. In Italy, resident foreigners are entitled to benefit from medical assistance under the same conditions as Italian citizens [33], while nonresident migrants are allowed to receive only urgent and/or essential medical care, including any preventive intervention aimed at protecting individual and public health [34]. In this context, the design of projects with preventive interventions specifically for migrant populations is crucial. Consistently, we found that the level of attention to health inequalities is higher on the prevention policy agenda in those Regions where migrants are numerous. It should be noted that, on arrival, migrants show, on average, better levels of health than nativeborn citizens, mainly because they are young and are seeking work [35-37]. This 'healthy immigrant effect', however, diminishes progressively as the immigrants assimilate the dominant culture and habits of the host nation, with their health status converging to that of native-born residents [38-40]. Therefore, improving the surveillance of the health of migrants, in particular through tailored programs of primary and secondary prevention among ethnic groups at higher risk, is essential from a public health perspective.

Central and Insular Regions and, to a lesser extent, Southern Regions developed projects with a lower level of attention to health inequalities. Geographical inequality in Italy is still one of the most discussed topics in Italian politics and public debates, and the gap between more developed Northern and less developed Southern Regions has not yet been closed. The most recent National Health Interview Survey, performed in Italy in 2013 [41], found an unequal distribution of health status, with better conditions in the Northern Regions than in Central and Southern Regions, the latter of which have the highest rates of hospitalization for both native Italians and immigrants, in particular for chronic diseases [42]. This North-south divide intensified after the decentralization of the Italian National Health System, such that a typical healthcare sector in the Southern Regions is less efficient and has a lower standard of care than counterparts in the Northern and Central Regions [43-45], mainly because of lower financial resources, but also due to cultural differences, socioeconomic development and technological infrastructure [23]. Therefore, in Central and Southern Regions, the implementation of preventive interventions aimed at improving living conditions and access to quality healthcare are strongly needed, since it has been proved that such a regional policy may reduce health disparities [46].

Our results show that Regions with higher RHCE as a proportion of GDP devote greater attention to health inequalities. We demonstrated previously that even lifestyle surveillance systems are more likely to be used in those Regions in this category [16]. However, tackling health inequalities could generate cost-saving health benefits in the long-term. The economic losses that health inequalities generate in Europe have been estimated recently and are substantial, both in absolute ( $€ 1000$ billion) and in relative terms (9.4\% of GDP) [47]. Therefore, the design of strategies and interventions aimed at reducing health inequalities deserves to be placed higher on the European and Italian policy agenda [48].

Our finding that the less civic Regions give more attention to health inequalities in the prevention planning process would seem counterintuitive. As stated, we used a characteristic of social capital called 'linking social capital' to represent the capacity of the population to establish 'vertical' connection across power gradients, especially with representatives of institutions [49]. A possible explanation of this finding could be that Regions with less social capital have a stronger commitment to the welfare state. It has been argued that a strong welfare state has a negative impact on social capital, since it could replace social relationships, social trust, and civic activities [50, 51]. The basic argument is that both the need and incentives for the creation and maintenance of social contacts and civic activities decrease when the welfare state takes on responsibilities and duties that previously derived from people's social networks and associations [52, 53].

Finally, the larger number of projects addressing health inequalities in the macroarea of 'prevention in high risk groups' deserves a comment. There is increasing evidence that screening programs intended to identify individuals with the highest levels of risk factors can widen health inequalities [9]. These interventions (e.g., behavioral change programs) require strong individual resources, both material and psychological, and thus tend to increase social inequalities [54-56]. This is particularly striking in cardiovascular disease prevention [9], but is also apparent in cancer prevention $[57,58]$. Therefore, it seems consistent that projects within the macroarea of 'prevention in highrisk groups' gave more attention to health inequalities. By contrast, universal prevention projects may reduce social inequalities, in particular by means of structural strategies that work through changes in the wider social environment $[9,50]$.

\section{Conclusions}

In conclusion, there is a low level of attention to health inequalities in the regional planning of prevention activities in Italy. This low level is particularly accentuated in Central and Southern Regions and is associated with a lower percentage of migrants, with a lower $\mathrm{HCE}$ as a percentage of RGDP and with a higher level of civicness. Projects addressing health inequalities are highly concentrated in the macroarea of 'prevention in high risk groups'. The positive aspects of these results have been 
communicated to the Italian Ministry of Health and the new NPP 2014-2018 has taken account of the issues raised by this study, including the contrast in health inequalities among the five macro-objectives of the plan. In this respect, Italy might represent a good example of how public health research can support effective policies and interventions able to reduce health inequalities.

\section{Abbreviations}

NPP: National Prevention Plan; RGDP: Regional Gross Domestic Product; RHCE: Regional Health Care Expenditure; RPP: Regional Prevention Plan.

\section{Competing interests}

The authors declare that they have no competing interests.

\section{Authors' contributions}

CDV made a substantial contribution to the study design, performed the statistical analysis and drafted the manuscript. AM and DDT participated in the design of the study, in the acquisition of data and in analysis and interpretation of data. AR EDA and MRV participated in the design of the study and in the acquisition of data. PV conceived the study, participated in its design and was involved in drafting the manuscript and revising it critically for important intellectual content. CM designed the study, helped to analyze and interpret data and to draft the manuscript. All authors read and approved the final manuscript.

\section{Acknowledgements}

This work was supported by the Italian Ministry of Health, 2012, within the project: 'Analisi ragionata dei piani regionali della prevenzione (PRP) previsti dal Piano Nazionale della Prevenzione 2010/2012 (PNP): elaborazione di una griglia di analisi evidence-based, esame specifico dei singoli PRP e delle diverse attività progettuali, indicazioni operative ai fini di future riprogrammazioni' (Analysis of RPPs provided by the NPP 2010-2012: development of an evidencebased assessment tool, specific examination of individual RPPs and projects, operational guidance for future reprogramming).

Received: 15 August 2015 Accepted: 11 February 2016

\section{Published online: 19 February 2016}

\section{References}

1. Mackenbach JP, Stirbu I, Roskam AJ, Schaap MM, Menvielle G, Leinsalu M, et al. Socioeconomic inequalities in health in 22 European countries. N Engl J Med. 2008;358:2468-81.

2. Mackenbach JP, Bakker MJ. Tackling socioeconomic inequalities in health: an analysis of recent European experiences. Lancet. 2003;362:1409-14.

3. Costa G, Faggiano F. L'equità nella salute in Italia. Rapporto sulle diseguaglianze sociali in sanità. [Health equity in Italy. Report on social inequalities in health]. Rome: FrancoAngeli; 1994.

4. Caiazzo A, Cardano M, Cois E, Costa G, Marinacci C, Spadea T, et al. Inequalities in health in Italy. Epidemiol Prev. 2004;28(3 Suppl):i-ix. 1-161.

5. Costa G, Bassi M, Gensini GF, Marra M, Nicelli AL, Zengarini N. L'equità nella salute in Italia. Secondo rapporto sulle disuguaglianze sociali in Sanità. [Health equity in Italy. Second report on social inequalities in health]. Rome: FrancoAngeli; 2014.

6. Graham H. Health inequalities, social determinants and public health policy. Policy Polit. 2009;37:463-79.

7. Vos T, Barber RM, Bell B, et al. Global, regional, and national incidence, prevalence, and years lived with disability for 301 acute and chronic diseases and injuries in 188 countries, 1990-2013: a systematic analysis for the Global Burden of Disease Study 2013. Global Burden of Disease Study 2013 Collaborators. Lancet. 2015;22:743-800.

8. Newton JN, Briggs AD, Murray CJ, et al. Changes in health in England, with analysis by English regions and areas of deprivation, 1990-2013: a systematic analysis for the Global Burden of Disease Study 2013. Lancet. 2015;386:2257-74

9. Capewell S, Graham H. Will cardiovascular disease prevention widen health inequalities? PLoS Med. 2010;7, e1000320.

10. Bambra C, Gibson M, Sowden A, Wright K, Whitehead M, Petticrew M Tackling the wider social determinants of health and health inequalities: evidence from systematic reviews. J Epidemiol Community Health. 2010;64: 284-91.

11. Kivimaki M, Shipley MJ, Ferrie JE, Singh-Manoux A, Batty GD, Chandola T, et al. Best-practice interventions to reduce socioeconomic inequalities of coronary heart disease mortality in UK: a prospective occupational cohort study. Lancet. 2008;372:1648-54.

12. Dowd JB, Aiello AE. Did national folic acid fortification reduce socioeconomic and racial disparities in folate status in the US? Int J Epid. 2008;37:1059-66.

13. NHS CRD. Systematic review of the efficacy and safety of the fluoridation of drinking water. Report 18. York: NHS Centre for Reviews and Dissemination, University of York; 2000.

14. Boccia A, De Vito C, Marzuillo C, Ricciardi W, Villari P. The governance of prevention in Italy. EBPH. 2013;10:e89141-2 (http://dx.doi.org/10.2427/8814).

15. Rosso A, Marzuillo C, Massimi A, De Vito C, de Belvis AG, La Torre G, et al. Policy and planning of prevention in Italy: results from a critical appraisal of prevention plans developed by Regions for the period 2010-2012. Health Policy. 2015;119:760-9.

16. Unim B, De Vito C, Massimi A, D'Andrea E, Rosso A, Villari $P$, et al. The need to improve implementation and use of lifestyle surveillance systems for planning prevention activities: an analysis of the Italian Regions. Public Health. 2016;130:51-8.

17. Dans AM, Dans L, Oxman AD, Robinson V, Acuin J, Tugwell P, et al. Assessing equity in clinical practice guidelines. J Clin Epidemiol. 2007;60:540-6.

18. Tugwell P, Petticrew M, Robinson V, Kristjansson E, Maxwell L, Cochrane Equity Field Editorial Team. Cochrane and Campbell Collaboration, and health equity. Lancet. 2006;367:1128-30.

19. Kavanagh J, Oliver S, Lorenc T. Reflections on developing and using PROGRESS-Plus. Equity Update. 2008;2:1-3.

20. Costa G, Gelormino E, Marra M. Strumento per l'attenzione all'equità dei progetti di prevenzione. [Tool for attention to equity in prevention projects]. Available at: www.epicentro.iss.it/stumenti/pdf/ CCMstrumentoequit\%C3\%A022marzo.pdf. (Last accessed on 15 June 2015).

21. Rosso A, De Vito C, Marzuillo C, Massimi A, D'Andrea E, Villari P. The negative effect of financial constraints on planning prevention activities: some evidence from the Italian experience. Eur J Public Health. 2015;25: 1117-9.

22. Italian National Institute of Statistics (ISTAT). Noi Italia 2012. Data available at: http://www3.istat.it/dati/catalogo/20120215_00/Noi_Italia_2012.pdf (Last accessed on 20 July 2015).

23. Putnam R, Leonardi R, Nanetti RY. Making Democracy Work: Civic Traditions in Modern Italy. Princeton: Princeton University Press; 1993.

24. Istat. La vita quotidiana nel 2007. [Daily life in 2007]. Rome: Istat; 2008

25. Sabatini F. II capitale sociale nelle regioni italiane: un'analisi comparata. [The social capital in Italian Regions: a comparative analysis]. Riv Polit Econ. 2009; 99:167-220 (http://www.socialcapitalgateway.org/sites/socialcapitalgateway. org/files/data/paper/2011/08/02/ilcapitalesocialenelleregioniitaliane.pdf). Accessed 20 Jul 2015.

26. Degli Antoni G, Sacconi L. A Theoretical Analysis of the Relationship between Social Capital and Corporate Social Responsibility: Concepts and Definitions. In: Sacchetti S, Sugden R, editors. Knowledge in the Development of Economies. Celtenham: Edward Elgar; 2009. p. 134-57.

27. Sabatini $F$. The relationship between trust and networks. An exploratory empirical analysis. Econ Bull. 2009;29:674-85 (http://www.accessecon.com/ Pubs/EB/2009/Volume29/EB-09-V29-12-P17.pdf). Accessed 20 Jul 2015.

28. De Blasio G, Nuzzo G. Historical traditions of civicness and local economic development. J Reg Sci. 2010;50:833-57.

29. WHO. Health 2020: a European policy framework supporting action across government and society for health and well-being. Copenhagen: WHO Regional Office for Europe; 2012.

30. Jakab Z. Promoting health and reducing health inequities in Europe. Lancet. 2012;380:951-3.

31. Gore DM, Kothari AR. Getting to the root of the problem: health promotion strategies to address the social determinants of health. Can J Public Health. 2013;104:e52-4.

32. Baum F, Fisher M. Are the national preventive health initiatives likely to reduce health inequities? Aust J Prim Health. 2011;17:320-6.

33. Italian Official Journal. Art. 34 of the Legislative Decree "Testo unico delle disposizioni concernenti la disciplina dell'immigrazione e norme sulla condizione dello straniero" [Consolidated text of provisions governing immigration and the status of foreigners No. 286 of 1998. GU 1998;191. 
34. European Union Agency for Fundamental Rights. Migrants in an irregular situation: access to healthcare in 10 European Union Member States. Luxembourg: Publications Office of the European Union, 2011. Available at: http://fra.europa.eu/sites/default/files/fra uploads/1925-FRA-2011fundamental-rights-for-irregular-migrants-healthcare_EN.pdf. (Last accessed on 20 July 2015).

35. Marmot MG, Adelstein MA, Bulusu L. Lessons from the study of immigrant mortality. Lancet. 1984;323:1455-7.

36. Lu Y. Test of the 'healthy migrant hypothesis': a longitudinal analysis of health selectivity of internal migration in Indonesia. Soc Sci Med. 2008;67: 1331-9.

37. Malmusi D, Borrell C, Benach J. Migration-related health inequalities: showing the complex interactions between gender, social class and place of origin. Soc Sci Med. 2010;71:1610-9.

38. Uretsky MC, Mathiesen SG. The effects of years lived in the United States on the general health status of California's foreign-born populations. J Immigr Minor Health. 2007:9:125-36.

39. Okrainec K, Bell CM, Hollands S, Booth GL. Risk of cardiovascular events and mortality among a population-based cohort of immigrants and long-term residents with diabetes: are all immigrants healthier and if so, for how long? Am Heart J. 2015;170:123-32.

40. Fedeli U, Ferroni E, Pigato M, Avossa F, Saugo M. Causes of mortality across different immigrant groups in Northeastern Italy. PeerJ. 2015;3, e975. doi:10.7717/peerj.975.

41. Istat. Aspetti della vita quotidiana. 2013. [Aspects of daily life, 2013]. Available at: www.istat.it/en/archive/129959. (Last accessed on 20 July 2015).

42. de Waure C, Bruno S, Furia G, Di Sciullo L, Carovillano S, Specchia ML, et al. Health inequalities: an analysis of hospitalizations with respect to migrant status, gender and geographical area. BMC Int Health Hum Rights. 2015;15:2.

43. Lega F, Mauri M, Prenestini A. L'ospedale tra presente e futuro. Analisi, diagnosi e linee di cambiamento per il sistema ospedaliero italiano. Milan: Egea; 2010.

44. Italian Ministry of Health and WHO. Health facts and policies in Italy in the European context. Rome: Italian Ministry of Health and WHO Regional Office for Europe; 2003.

45. Giannoni M, Hitiris T. The regional impact of health care expenditure: the case of Italy. Appl Econ. 2002;34:1829-36.

46. Franzini L, Giannoni M. Determinants of health disparities between Italian Regions. BMC Public Health. 2010;10:296.

47. Mackenbach JP, Meerding WJ, Kunst AE. Economic costs of health inequalities in the European Union. J Epidemiol Community Health. 2011;65: 412-9.

48. Mackenbach JP, Meerding WJ, Kunst AE. Economic Implications of Socioeconomic Inequalities in Health in the European Union. Brussels: European Commission; 2007. Available at: http://ec.europa.eu/health/ph_ determinants/socio_economics/documents/socioeco_inequalities_en.pdf. (Last accessed 20 July 2015).

49. Szreter S, Woolcock M. Health by association? Social capital, social theory, and the political economy of public health. Int J Epidemiol. 2004;33:650-67.

50. Fukuyama F. Social capital and civic society: IMF working paper No. 00/74. Washington DC, 2000. www.imf.org/external/pubs/ft/wp/2000/wp0074.pdf (Last accessed 8 December 2015).

51. Scheepers P, Grotenhuis MT, Gelissen J. Welfare states and dimensions of social capital: cross-national comparisons of social contacts in European countries. Eur Soc. 2002:42:185.

52. Van der Meer T, Scheepers P, Grotenhuis M. States as molders of informal relations? A multilevel test on social participation in 20 Western Countries. Eur Soc. 2009;11:233-55.

53. McLaren L, Mclntyre L, Kirkpatrick S. Rose's population strategy of prevention need not increase social inequalities in health. Int J Epidemiol. 2010;39:372-7.

54. Rostila M. Social capital and health inequality in European welfare state. New York: Palgrave Macmillan; 2013.

55. Blaxter M. Evidence for the effect on inequalities in health of interventions designed to change behaviour. Bristol: Department of Social Medicine, University of Bristol. NICE BC 6-5, 2007. Available at: https://www.nice.org. uk/guidance/ph6/documents/evidence-for-the-effect-on-inequalitiesdesigned-to-change-behaviour2 (Last accessed 20 July 2015).
56. White M, Adams J, Heywood P. How and why do interventions that increase health overall widen inequalities within populations? In: Babones S, editor. Health, inequality and society. Bristol: Policy Press; 2009.

57. Banks E, Beral V, Cameron R, Hogg A, Langley N, Barnes I, et al. Comparison of various characteristics of women who do and do not attend for breast cancer screening. Breast Cancer Res. 2002;4:R1.

58. Al-Kaabi R, Gamboa AB, Williams D, Marcenes W. Social inequalities in oral cancer literacy in an adult population in a multicultural deprived area of the UK. J Public Health (Oxf). 2015. [Epub ahead of print].

\section{Submit your next manuscript to BioMed Central and we will help you at every step:}

- We accept pre-submission inquiries

- Our selector tool helps you to find the most relevant journal

- We provide round the clock customer support

- Convenient online submission

- Thorough peer review

- Inclusion in PubMed and all major indexing services

- Maximum visibility for your research

Submit your manuscript at www.biomedcentral.com/submit
Biomed Central 